\title{
Microbiota do solo na tolerância de doenças em plantas: Uma revisão
}

\author{
Soill microbiota on disease tolerance in plants: A review \\ La microbiota del suelo sobre la tolerancia a enfermedades en plantas: Una revisión
}

Recebido: 14/06/2021 | Revisado: 22/06/2021 | Aceito: 28/06/2021 | Publicado: 11/07/2021

\author{
Vinicius Villa e Vila \\ ORCID: https://orcid.org/0000-0001-8757-8195 \\ Universidade Estadual de Maringá, Brasil \\ E-mail: vinivilla95@hotmail.com \\ Roberto Rezende \\ ORCID: https://orcid.org/0000-0002-6213-1845 \\ Universidade Estadual de Maringá, Brasil \\ E-mail: rrezende@uem.br \\ Lucas Henrique Maldonado da Silva \\ ORCID: https://orcid.org/0000-0002-8835-3868 \\ Universidade Estadual de Maringá, Brasil \\ E-mail: lucasmaldonado7@gmail.com \\ Raiana Crepaldi de Faria Nocchi \\ ORCID: https://orcid.org/0000-0002-5257-9363 \\ Universidade Estadual de Maringá, Brasil \\ E-mail: raianacdef@hotmail.com \\ André Felipe Barion Andrean \\ ORCID: https://orcid.org/0000-0003-3403-2951 \\ Universidade Estadual de Maringá, Brasil \\ E-mail: andre_andrean@hotmail.com \\ Gustavo Soares Wenneck \\ ORCID: https://orcid.org/0000-0002-4151-2358 \\ Universidade Estadual de Maringá, Brasil \\ E-mail: gustavowenneck@gmail.com \\ Daniele de Souza Terassi \\ ORCID: https://orcid.org/0000-0003-4674-8834 \\ Universidade Estadual de Maringá, Brasil \\ E-mail: daniele_terassi@hotmail.com \\ Paula Toshimi Matumoto Pintro \\ ORCID: https://orcid.org/0000-0002-9182-5758 \\ Universidade Estadual de Maringá, Brasil \\ E-mail: ptmpintro@uem.br
}

\begin{abstract}
Resumo
Interações entre a planta e a microbiota na rizosfera são um dos principais fatores determinantes da sanidade das plantas e da fertilidade do solo. A microbiota é complexa, compreendem numerosos micro-organismos, dentre eles, as micorrizas arbusculares e os rizóbios são de grande importância para a sanidade e produtividade vegetal. O objetivo desta revisão foi caracterizar as relações simbióticas micorrízicas e das bactérias fixadoras de nitrogênio e suas relações com a tolerância de doenças em planta. Através de revisão de literatura de caráter qualitativo, foi reunido informações sobre os efeitos da microbiota na tolerância de doenças em plantas. Segundo a literatura revisada, as micorrizas arbusculares que são simbioses microbianas, quando se encontram sob condições de limitação de fósforo, influenciam o desenvolvimento da comunidade vegetal, a absorção de nutrientes, as relações hídricas e a produtividade. As micorrizas também atuam como bioprotetores contra os estresses abióticos e bióticos, além da ativação dos mecanismos de defesa da planta com a resistência induzida. Rizóbios também podem ser considerados agentes de biocontrole, contribuindo para sanidade das plantas por meio da inibição direta de uma ampla gama de fitopatógenos, por exemplo como observado pelo mecanismo de resistência sistêmica induzida. A simbiose estimula a síntese de metabólitos que atuam protegendo as raízes contra fitopatógenos por meio de antibiose e liberação de exsudatos. Conclui-se que ambas simbioses contribuem para práticas de cultivo mais sustentáveis, para o aumento da produção e redução da incidência de fitopatógenos.
\end{abstract}

Palavras-chave: Micorrizas; Micro-organismos do solo; Resistência sistêmica induzida; Rizóbios.

\begin{abstract}
Interactions between plants and microbiota in the rhizosphere are one of the most important factors of plants sanity and soil fertility. The microbiota is complex, comprising numerous microorganisms, including arbuscular mycorrhizae and rhizobia are of great importance for plant health and productivity. The aim of this review was to characterize the symbiotic mycorrhizal and nitrogen-fixing bacteria and their relationship with plant diseases tolerance. Through a
\end{abstract}


qualitative literature review, information on the effects of microbiota on plant disease tolerance was compiled. According to the reviewed literature, arbuscular mycorrhizae symbiosis, in phosphorus limiting condition, influences the vegetal community development, nutrients absorption, water relations and productivity. Mycorrhizae act as bio protectors against biotic and abiotic stress, beyond activation of plant defense mechanisms through induced resistance. Rhizobia can be considered biocontrol agents, contributing for plant sanity through the direct inhibition of phytopathogens, as observed by the mechanism of induced systemic resistance. Symbiosis stimulate the synthesis of metabolites that act protecting roots against phytopathogens through antibiosis and exudates liberation. It has concluded that both symbiosis contribute to more sustainable cultivation practices, to increase production and reduce the incidence of phytopathogens.

Keywords: Mycorrhizae; Soil microorganisms; Induced systemic resistance; Rhizobia.

\section{Resumen}

Las Interacciones entre las plantas y la microbiota de la rizosfera son uno de los principales determinantes de la sanidad de las plantas y la fertilidad del suelo. La microbiota es compleja y comprende numerosos microorganismos, incluidas las micorrizas arbusculares y los rizobios, que son de gran importancia para la sanidad y la productividad de las plantas. El objetivo de esta revisión fue caracterizar las relaciones simbióticas micorrízicas y las bacterias fijadoras de nitrógeno y sus relaciones con la tolerancia a enfermedades de las plantas. Mediante una revisión cualitativa de la literatura, se recopiló información sobre los efectos de la microbiota en la tolerancia a las enfermedades de las plantas. Según la literatura, las micorrizas arbusculares simbiosis, en condiciones de limitación de fósforo, influyen en el desarrollo de la comunidad vegetal, la absorción de nutrientes, las relaciones hídricas y la productividad. Las micorrizas también actúan como bioprotectores frente a estreses abióticos y bióticos, además de activar los mecanismos de defensa de la planta con resistencia inducida. Los rizobios pueden considerarse agentes de biocontrol, contribuyendo a la sanidad de las plantas a través de la inhibición directa de una amplia gama de fitopatógenos, por ejemplo como se observa por el mecanismo de resistencia sistémica inducida, por la simbiosis que estimula la síntesis de metabolitos que actúan para proteger las raíces frente a fitopatógenos mediante antibiosis y liberación de exudados. Se concluye que ambas simbiosis contribuyen a prácticas de cultivo más sustentables, para incrementar la producción y reducir la incidencia de fitopatógenos.

Palabras clave: Micorrizas; Microorganismos del suelo; Resistencia sistémica inducida; Rizobios.

\section{Introdução}

Os solos tropicais, em função de características edafoclimáticas e de manejo agrícola, podem apresentar limitação produtiva, seja pelos baixos teores de nutrientes, acidez, presença de alumínio tóxico, elevado grau de erodibilidade, baixo teor de matéria orgânica e baixa atividade biológica que compromete a produção de alimentos (Cardoso \& Kuyper, 2006). Uma alta atividade biológica pode indicar que o solo apresenta maior potencial produtivo.

A microbiota do solo é complexa, numerosos micro-organismos habitam a rizosfera, como proteobactérias, bactérias fixadoras de nitrogênio, bactérias promotoras de crescimento de plantas e fungos micorrízicos. Vários são os fatores que contribuem para a existência e sobrevivência desses micro-organismos, como boas práticas agrícolas (Omotayo \& Babalola, 2020). É nesse local, denominado rizosfera, zona ao redor das raízes que é diretamente influenciada pelos exsudatos das raízes das plantas, cujas atividades microbianas são fundamentais para o funcionamento das plantas, auxiliando na absorção de nutrientes e protegendo contra fitopatógenos (Khatoon, et al., 2020).

A planta, o solo e sua microbiota interagem para realizar e influenciar vários processos que contribuem com a sanidade e a produtividade da planta. Alguns exsudatos de raiz funcionam como sinais tanto como antagonismo de fitopatógenos quanto para agregar micro-organismos benéficos (Ahmed, et al., 2019). A microbiota associada às plantas desempenha papel vital na regulação de vários processos biológicos que estão envolvidas no crescimento e desenvolvimento das plantas, bem como nas respostas das plantas a condições adversas, provocadas por fatores bióticos e abióticos (Tian, et al., 2020). A diversidade da microbiota do solo, está associada às raízes das plantas e desempenham papel importante na supressão de fitopatógenos transmitidos pelo solo, além de aumentar a eficácia de supressão de doenças (Hu, et al., 2016).

As micorrizas são relações simbióticas entre fungos específicos e raízes de plantas, ocupando diversos ecossistemas, que durante milhões de anos foram gerados quatro tipos principais de micorrizas, sendo as micorrizas arbusculares, ectomicorrizas, micorrizas de orquídeas e micorrizas ericoides que surgiram em diferentes momentos durante a evolução das 
plantas e se diferenciaram por características morfológicas (Genre, et al., 2020).

As micorrízas arbusculares são de maior importância quando se trata de plantas de interesse agronômico, sendo um dos assuntos chaves desta revisão. Além de mecanismos nutricionais, as micorrizas ativam sistemas de defesa da planta, promovem mudanças nos padrões de exsudação e na população da microbiota da rizosfera, além de competir por espaços para colonização e locais de infecção (Cardoso \& Kuyper, 2006).

Os rizóbios são bactérias do solo que se envolvem em uma simbiose mutualística com as plantas e beneficiam o hospedeiro ao fixar o $\mathrm{N}$ atmosférico. Além disso, os rizóbios podem ser considerados agentes de biocontrole, contribuindo para a sanidade das plantas por meio da inibição de fitopatógenos. O processo de infecção da microbiota da rizosfera nas raízes e o desenvolvimento de simbiose também pode acarretar num aumento do estado de defesa sistêmica da planta, esse processo é semelhante à resistência sistêmica induzida (Tonelli, et al., 2020).

Esta revisão de literatura teve como objetivo caracterizar as relações simbióticas micorrízicas e das bactérias fixadoras de nitrogênio e suas relações com a tolerância de doenças em plantas.

\section{Metodologia}

Esta revisão de literatura, de caráter qualitativo (Pereira, et al., 2018), buscou reunir resultados de diversas produções científicas a respeito do efeito da microbiota do solo na tolerância a doenças em plantas, a partir de buscas nas bases de dados, Science Direct, Google Acadêmico, Periódicos CAPES e SciELO, priorizando artigos, de revistas internacionais e nacionais dos últimos dez anos, poucos artigos mais antigos foram utilizados por conterem informações importantes. Utilizou-se de palavras-chave como, micorrizas, rizóbios, biota do solo, microbiota do solo, resistência sistêmica, resistência sistêmica induzida, rizosfera, foram selecionados 43 artigos de acordo com as variáveis de interesse, contemplando informações relevantes sobre os efeitos da microbiota na tolerância de doenças em plantas.

\section{Revisão de literatura}

\subsection{Micorrizas arbusculares: conceito, formação e seus benefícios paras as plantas}

Fungos micorrízicos arbusculares (FMA) são importantes simbiontes de plantas, tendo suas origens datando mais de 400 milhões de anos, fornecendo vários benefícios às plantas hospedeiras, como uma absorção eficiente de água e nutrientes do solo (Bonfante \& Genre, 2010). Outra função relacionada a formação de micorrizas em plantas são os mecanismos de tolerância a doenças (Liu, et al., 2007). Estes são fungos biotróficos obrigatórios que requerem uma planta hospedeira para completar seu ciclo de vida (Jung, et al., 2012).

A simbiose entre os FMA e as raízes de plantas são caracterizados pela formação de estruturas altamente ramificadas para troca de nutrientes entre os simbiontes, chamados arbúsculos (Campos, 2020). Os FMA são um grupo heterogêneo de diversos táxons de fungos, podendo estabelecer associações mutualísticas com as raízes de mais de $80 \%$ de todas as famílias de plantas terrestres (Lin, et al., 2020), envolvendo cerca de 340.000 espécies vegetais (Genre, et al., 2020).

Existem duas fases morfológicas diferentes de FMA, dentro da raiz e no solo, sendo o micélio intraradical que consiste em hifas e outras estruturas fúngicas, que são locais de troca de nutrientes e carbono entre os simbiontes, e vesículas, locais de armazenamento de lipídios para o fungo, e o micélio intraradical que é conectado ao micélio do solo, no qual o micélio extraradical explora o solo e novas áreas para colonização e absorve nutrientes (Rillig, 2004).

Mudanças fisiológicas ocorrem na planta hospedeira após a colonização da raiz afetando as interações com uma ampla gama de organismos abaixo e acima da superfície do solo, além de mecanismos capazes de melhorar a absorção de nutrientes pelas plantas. Durante o estabelecimento do FMA ocorre a modulação das respostas de defesa da planta, alcançando assim uma simbiose funcional, e como consequência, ocorre ativação das respostas imunes da planta, no local e também 
sistemicamente (Jung, et al., 2012).

Grandes efeitos positivos são resultantes da simbiose micorrizica arbuscular, promovendo benefícios tanto no crescimento e desenvolvimento da planta, como o aumento de sua biomassa, melhor aquisição de nutrientes, maior tolerância a estresses abióticos e maior tolerância a doenças e ataque de patógenos, pela produção de ácido jasmônico, ácido salicílico, indução de resistência sistêmica e produção de compostos de defesa (Jacott, et al., 2017). Sob estresses bióticos os FMA competem por locais de colonização, melhoram o sistema de defesa da planta, auxiliando na indução de resistência (Diagne, et al., 2020).

\subsubsection{Importância da formação de micorrizas arbusculares para o crescimento e nutrição das plantas}

Um dos fatores que promovem bom crescimento e desenvolvimento das plantas se deve à associação e comunicação da microbiota do solo com raízes de plantas dentro da rizosfera, pois os exsudatos de raízes são substratos de crescimento essenciais para microrganismos do solo que desempenham um papel importante no ciclo de vida das plantas, bem como na indução de defesas contra fitopatógenos (Khatoon, et al., 2020).

Uma variedade de mecanismos tem sido proposta para explicar o papel protetor dos fungos micorrízicos, um desses mecanismos, é nutricional, sendo que plantas bem nutridas são mais tolerantes a ataques de doenças e pragas. A baixa disponibilidade de fósforo $(\mathrm{P})$ limita o crescimento de plantas, a deficiência de $\mathrm{P}$ é causada principalmente por forte adsorção de fósforo em óxidos de alumínio $(\mathrm{Al})$ e ferro $(\mathrm{Fe})$, que transforma grandes proporções do $\mathrm{P}$ total em formas não disponíveis para as plantas. $\mathrm{O}$ aumento da absorção de $\mathrm{P}$ das plantas tem sido o efeito benéfico mais reconhecido dos FMA, uma exploração física mais ampla do solo por fungos micorrízicos do que por raízes (Cardoso \& Kuyper, 2006).

Chandrasekaran (2020), analisou dados entre plantas micorrizadas e não micorrizadas, as plantas micorrizadas aumentaram significativamente a absorção de fósforo, nitrogênio e potássio em 36,3\%, 22,1\% e 18,5\%, respectivamente, como também houve aumento significativo da parte aérea, raiz e biomassa total de 36,3\%, 28,5\% e 29,7\%, respectivamente. As espécies de fungos que mais intensificaram os parâmetros de crescimento da planta foram o Rhizophagus fasciculatus e Funniliforme mosseae, e as plantas que tiveram as melhores respostas foram o Triticum aestivum e Solanum lycopersicum.

\subsubsection{Papel das micorrizas arbusculares na tolerância a estresses}

Os mecanismos não nutricionais de proteção das plantas também são importantes, pois plantas micorrizadas e não micorrizadas com mesmo estado nutricional de fósforo, podem responder diferentemente a patógenos. Alguns mecanismos não nutricionais são a ativação dos sistemas de defesa, mudanças nos padrões de exsudação e nas populações da microbiota da rizosfera, aumento do teor de lignina das paredes celulares e competição por colonização e locais de infecção (Cardoso \& Kuyper, 2006).

Mathur e Jajoo (2020), observaram a importância da micorrização em plantas em ambiente estressante por altas temperaturas, relatando que plantas que tinham associações micorrízicas apresentaram sistema radicular mais desenvolvido para absorção de água em altas temperaturas e maior capacidade de assegurar alta capacidade fotossintética, através da regulação da heterogeneidade do fotossistema II.

Na revisão de Evelin et al. (2009), sobre a interação dos fungos micorrízicos em ambiente com salinização do solo, foi abordado a importância da micorriza arbuscular na redução do estresse salino e seus efeitos benéficos no crescimento e na produtividade das plantas, alguns dos mecanismos relatados foram maior aquisição de nutrientes, alterações bioquímicas, alterações fisiológicas e alterações moleculares. 


\subsubsection{Micorrizas e seus impactos na tolerância de doenças em plantas}

O primeiro mecanismo proposto para estar envolvido na proteção de doenças por meio das micorrizas foi a melhoria da nutrição das plantas e a consequente compensação dos danos causados pelo fitopatógeno (Pozo, et al., 2010). Outro fator que foi sugerido é que a planta apresenta certa resistência induzida contra patógenos de raiz devido à competição direta por espaço de colonização e recursos (Bødker, et al., 2002).

É explicado também que essa proteção é baseada não apenas na melhoria da nutrição ou mudanças locais nas raízes e na rizosfera, mas que o estímulo da imunidade das plantas desempenha um papel importante na resistência induzida por micorrizas. Embora a base molecular para a regulação das defesas das plantas durante a micorrização não é totalmente conhecido, confirmou-se uma rota de sinalização do jasmonato, molécula que desempenha um papel central na indução de resistência (Jung, et al., 2012). Conforme Cameron et al., (2013) esta resistência sistêmica induzida por micorrizas pode ser dividida em 4 fases (Figura 1).

Figura 1. Esquema do estabelecimento da resistência sistêmica induzida por FMA.

\begin{tabular}{|l|l|} 
(II) & $\begin{array}{l}\text { Fase I: Ocorre exsudação de estrigolactonas, induzindo a ramificação das } \\
\text { hifas em fungos micorrízicos arbusculares. }\end{array}$ \\
$\begin{array}{l}\text { Fase II: Os FMA iniciam a infecção do córtex da raiz, levando à } \\
\text { expressão transitória da imunidade desencadeada por padrões } \\
\text { moleculares (células vermelhas) e à geração de sinais de longa distância } \\
\text { nos tecidos vasculares (seta vermelha), estimulando um priming de longa } \\
\text { duração. }\end{array}$ \\
\hline (II)
\end{tabular}

Fonte: Cameron et al. (2013).

O esquema mostra o efeito protetor denominado de resistência induzida por micorriza, resultando uma proteção sistêmica contra fitopatógenos, exibindo inicialmente características de resistência adquirida sistêmica, conferida pela infecção por fitopatógenos e resistência sistêmica induzida, a partir da colonização de raízes pela microbiota benéfica do solo (Cameron, et al., 2013).

Segundo Pozo et al. (2010), além dos aspectos nutricionais, as mudanças que ocorrem na arquitetura da planta, na exsudação radicular e nas populações microbianas da rizosfera, podem ser relevantes para a tolerância a doenças. Os estudos demonstraram também redução da incidência de doenças como podridão ou murcha de raízes causadas por diversos fungos como Fusarium, Rhizoctonia, Macrophomina ou Verticillium, e bactéria, como Erwinia carotovora, através da formação de simbioses micorrízicas. O aumento da resistência contra patógenos de raízes foi observado por Sikes (2010), onde plantas de 
Setaria glauca que foram inoculadas com fungos micorrízicos da família Glomeraceae, foram efetivos por reduzir a presença de alguns patógenos de solo.

Kumari e Prabina (2019), na cultura do tomate (Lycopersicum esculentum), relataram que a produção de compostos antimicrobianos da raiz micorrizada interrompeu o crescimento micelial do patógeno, reduzindo a incidência da murcha, doença causada pelo fungo fitopatogênico Fusarium oxysporum, aumentando o crescimento da planta, o teor de N, P e K, o teor de clorofila e rendimento da planta.

Estudos realizados por Spagnoletti et al. (2020), demonstram que a severidade da doença da podridão radicular do carvão na soja, causada pelo fungo Macrophomina phaseolina, foi reduzida nas plantas em que houve inoculação com fungos micorrizicos, Rhizophagus intraradices além disso, aumentou a biomassa dessas plantas comparadas as plantas que não apresentavam simbiose. Miozzi et al. (2020), observaram o efeito da colonização de FMA da espécie Funneliformis mosseae na infecção pelo vírus do mosaico do pepino (CMV) no tomate, mostrando que o estabelecimento de uma simbiose funcional é capaz de limitar o desenvolvimento dos sintomas, mitiga a redução de genes relacionados a fotossíntese, também acarreta num aumento de ácido salicílico e uma modulação de genes que limitam o acúmulo de espécies reativas de oxigênio, denominando de efeito priming.

Song et al. (2015), relataram tolerância a Alternaria solani e Fusarium oxysporum em associações micorrízicas na cultura do tomateiro. Wang et al. (2017), observaram na cultura da batata que a presença de micorrizas elevou a resistência contra infecção de patógeno Cladosporium fulvum, consequentemente ocorreu um aumento no peso fresco, seco, no conteúdo total de clorofila e na taxa de fotossíntese das plantas que possuíam associações micorrizicas. Tian et al. (2019), mostraram que a inoculação com o fungo micorrizico Rhizoglomus intraradices reduziu a abundância relativa de fungos fitopatogênicos, e aumentou bactérias benéficas na região da rizosfera, em plantas de Panax ginseng.

\subsection{Rizóbios como promotores de crescimento em plantas}

A nitrificação é um processo essencial no ciclo do nitrogênio, sendo responsável pela conversão biológica da amônia $\left(\mathrm{NH}_{3}\right)$ em nitrato $\left(\mathrm{NO}_{3}{ }^{-}\right)$(Padrão, et al., 2019). A nitrificação no solo é geralmente considerada um processo de duas etapas em que a amônia é primeiro oxidada em nitrito por oxidantes de amônia e, posteriormente, em nitrato por bactérias oxidantes de nitrito ( $\mathrm{Li}$, et al., 2018). Sendo que o nitrogênio é um dos nutrientes mais importantes para o crescimento e desenvolvimento das plantas, é um dos elementos que apresentam grande demanda durante o ciclo produtivo das culturas.

O substrato e o produto final da nitrificação são fontes importantes para o crescimento microbiano e das culturas, e também contribuem para as perdas de N, como volatilização de amônia, lixiviação de nitrato, óxido nitroso e emissões de gás de óxido nítrico através das vias de oxidação de $\mathrm{NH}_{3}$ e desnitrificação (Ma, et al., 2020). Bactérias apresentam grande importância no processo de nitrificação nos solos, entretanto nesta revisão será dado ênfase às bactérias responsáveis ao processo de fixação biológica de $\mathrm{N}$.

Na região da rizosfera, uma simbiose de grande importância é entre as bactérias que fazem fixação biológica de N, do gênero Rhyzobium, em raízes de plantas leguminosas, da família Leguminoseae, resultando na formação de nódulos nas raízes, trazendo benefícios para os dois indivíduos, planta e micro-organismo, sendo assim todo o sistema produtivo é beneficiado (Manhaes \& Francelino, 2013). Hoje a fixação biológica de N é capaz de disponibilizar o nutriente em grande quantidade para plantas, com maior eficiência ecológica e menor custos.

\subsubsection{Processo de infecção da bactéria nas raízes e nodulação}

Os mecanismos moleculares subjacentes à simbiose rizóbio-leguminosa podem ser divididos em dois estágios principais: (I) formação e invasão de nódulos, processos distintos, mas bem coordenados, e (II) fixação simbiótica de 
nitrogênio que ocorre dentro das células dos nódulos. Essas simbioses são manifestadas pela formação de órgãos especializados de raiz chamados nódulos que são maciçamente colonizados por parceiros bacterianos e atuam como fábricas fixadoras de N em miniatura para a planta (Masson-Boivin \& Sachs, 2018).

A infecção das bactérias ocorre por meio de atração quimiostática, onde a raiz secreta flavonóides e betaínas que direcionam a bactéria à raiz, e nesta encontram-se lecitinas receptoras produzidas nos pelos radiculares (Figura 2), (Sergeevich, et al., 2015).

Figura 2. Processo inicial de infecção de bactérias fixadoras de $\mathrm{N}$ na raiz.

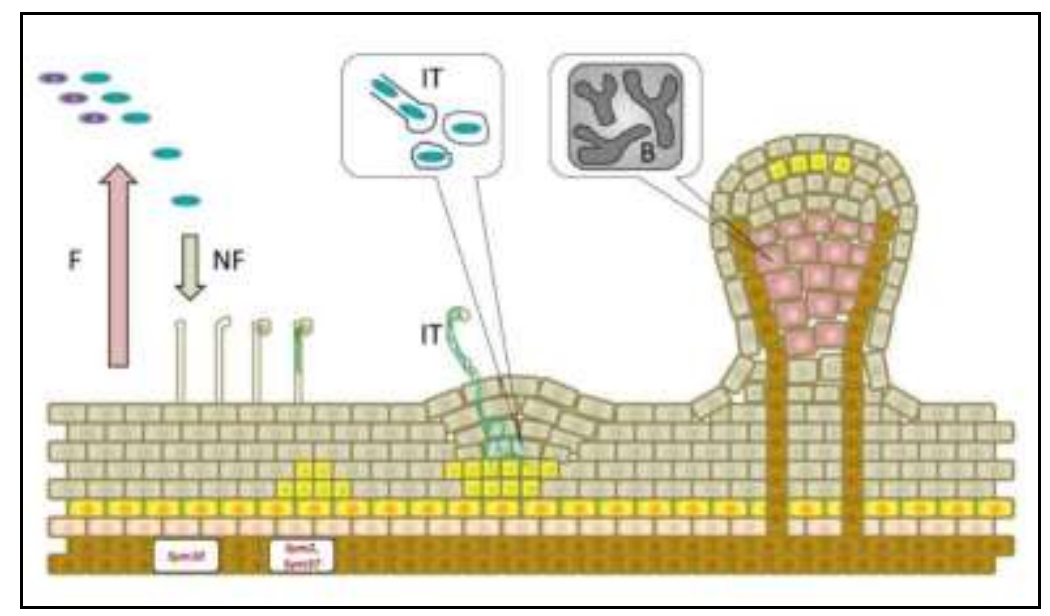

Legenda: F: Flavanóides; NF: Fatores de nodulação excretados pela bactéria; IT: Fio de infecção que promove a diferenciação do nódulo; B: Bacterióide. Fonte: Sergeevich et al. (2015).

Durante a atração da bactéria pela raiz, ocorre a transcrição dos genes Nod, e ao entrar em contato com os pelos radiculares são liberados os fatores de nodulação que induzem o enrolamento, em sequência ocorre a formação de primórdio nodular, com posterior divisão no citoplasma até o nódulo tornar-se maturo, o nódulo apresenta bacterióide que facilita as interações com a planta (Sergeevich, et al., 2015).

\subsubsection{Mecanismos das bactérias fixadoras de nitrogênio na tolerância de doenças em plantas}

Um solo saudável, apresenta populações de organismos que promovem o crescimento das plantas, como rizobactérias. Algumas funções delas são a ciclagem e absorção de nutrientes, a inibição de fitopatógenos, a estimulação do sistema imunológico da planta e o aumento do crescimento das plantas através da produção de fitormônios (Khatoon, et al., 2020).

Estas bactérias estimulam o crescimento, e melhoraram a qualidade do solo por meio da fixação de nitrogênio, solubilização de fosfato, sequestro de metal pesado, produção de fitormônios, mineralização da matéria orgânica do solo, decomposição de resíduos de culturas, supressão de fitopatógenos, entre outros (He, et al., 2019). As aplicações combinadas de diferentes espécies de rizobactérias também melhoram a saúde do solo e garantem uma agricultura sustentável em comparação com a aplicação de uma única espécie (Khatoon, et al., 2020). O uso de bactérias fixadoras de nitrogênio pode reduzir as aplicações de fertilizantes químicos, consequentemente diminuindo o custo de produção.

Benefícios da associação das bactérias com as plantas, foram descritos por Trivedi et al. (2020), cujas interações entre as plantas e sua microbiota endofítica é complexa, e sob condições de estresse biótico, as plantas podem alterar seus padrões de exsudação para recrutar seletivamente um microbioma tolerante ao estresse, refletindo em efeitos diretos que são mediados pela fixação de nitrogênio, no qual plantas leguminosas desenvolvem simbiose com bactérias fixadoras de $\mathrm{N}$. 
A infecção da raiz por algumas espécies de Rhizobium desencadeia reações de resistência induzida, essas reações estão associadas ao aumento da atividade de enzimas, como peroxidases e polifenol oxidase e à produção de fitoquímicos defensivos baseados em C, como fenólicos, flavonóides e fitoalexinas (Mabrouk, et al., 2018)

Karoney et al. (2020), observaram em seus experimentos que o Rhizobium melhora a nutrição e a tolerância de Phaseolus vulgaris a Colletotrichum lindemuthianum aumentando o teor de nitrogênio orgânico, concluindo que a infecção por Rhizobium no feijão comum aumenta a produção de $\mathrm{N}$, enquanto limita a produção de compostos orgânicos associados à resistência da planta, observando que houve incidência, mas sem redução no crescimento da planta.

Já Al-Ani et al. (2012), observaram que o Rhizobium japonicum atuou como agente de biocontrole da podridão radicular da soja causada por Fusarium solani e Macrophomina phaseolina, a semeadura de sementes revestidas de rizóbio em solo contaminado por esses fitopatógenos, aumentou no campo a germinação das sementes e induziu uma redução na severidade da doença, indicando que o rizóbio pode ser um elemento importante no manejo da podridão radicular. Descreveram ainda que os exsudatos promovem a síntese de metabólitos que protegerão as raízes contra fitopatógenos por meio de antibiose,

Os rizóbios podem ser considerados agentes de biocontrole, contribuindo para a fitossanidade das plantas por meio da inibição direta de ampla gama de fitopatógenos. Recentemente, tornou-se evidente que a invasão rizobiana das raízes das plantas também pode desencadear um aumento do estado de resistência sistêmica no hospedeiro, um processo semelhante ao mecanismo de resistência sistêmica induzida, onde algumas cepas de rizóbios produzem sideróforos contra bactérias e fungos do solo, levando um aumento do estado de defesa sistêmica da planta (Tonelli, et al., 2020).

Kalantari et al. (2018), observaram que a presença de Rhizobium leguminosarum na cultura do feijão (Phaseolus vulgaris) suprimiu a podridão da raiz causada por $F$. solani f. sp. phaseoli e aumentou o peso da planta e da raiz. Diaz-Valle et al. (2019), na cultura do feijão; inoculada com R. etli, observaram que a sintomatologia da doença causada por Pseudomonas syringae pv. phaseolicola e colonização de patógenos foram diminuídos, concluindo que a expressão de genes relacionados à defesa em plantas tratadas com R. etli exibiu um padrão que é típico da resposta de priming.

\section{Considerações Finais}

As formações micorrízicas atuam diante de todos os benefícios mencionados nesta revisão, contribuindo com práticas de cultivo mais sustentáveis, mantendo a produção vegetal e reduzindo patógenos sem impactos negativos ao meio ambiente. A fixação biológica de $\mathrm{N}$, traz benefícios diretos, capaz de disponibilizar o nutriente em grande quantidade para plantas com melhor eficiência ecológica e menor custos. Espécies de rizóbios com a simbiose, como agentes de biocontrole, desencadeiam reações de resistência induzidas que são inibidoras de fitopatógenos.

$\mathrm{O}$ desafio de aumentar a produtividade e, ao mesmo tempo, manter a estabilidade ambiental requer educar os agricultores e ajudá-los a compreender e adotar práticas agrícolas inovadoras e adequadas. O papel da microbiota do solo vem ganhando atenção devido à sua capacidade de potencializar o desenvolvimento das plantas e ao seu papel como agentes promissores para o controle do estresse em plantas.

É importante conhecer mecanismos de indução de resistência que as associações micorrízicas e a simbiose de bactérias fixadoras de nitrogênio com leguminosas ocasionam, sendo uma ferramenta de manejo cujo impacto está diretamente relacionado a agricultura em nível mundial. Revelar os princípios por trás destas simbioses e da interação entre planta e fungo ou bactéria é de grande interesse, e deve ser continuadamente estudado, em vista das implicações práticas quanto à eficácia no controle biológico e manejo integrado de doenças, auxiliando a agricultura moderna com práticas sustentáveis que visam um aumento vertical de produção e que seja suficiente para garantir a segurança alimentar humana sem impactos negativos no meio ambiente. 


\section{Agradecimentos}

Agradecimentos a Coordenação de Aperfeiçoamento Pessoal de Nível Superior (CAPES) pela concessão da bolsa de estudos, processo 001, e a Universidade estadual de Maringá (UEM).

\section{Referências}

Ahmed, T., Shahid, M., Noman, M., Hussain, S., Khan, M. A., Zubair, M., Ismail, M., Manzoor, N., Shahzad, T., \& Mahmood, F. (2019). Plant GrowthPromoting Rhizobacteria as Biological Tools for Nutrient Management and Soil Sustainability. Plant Growth Promoting Rhizobacteria for Agricultural Sustainability, 95-110. doi.org/10.1007/978-981-13-7553-8_5

Al-Ani, R. A., Adhab, M. A., Mahdi, M. H., \& Abood, H. M. (2012). Rhizobium japonicum as a biocontrol agent of soybean root rot disease caused by Fusarium solani and Macrophomina phaseolina. Plant Protection Science, 48(4), 149-155. doi.org/10.17221/16/2012-pps

Bødker, L., Kjøller, R., Kristensen, K., \& Rosendahl, S. (2002). Interactions between indigenous arbuscular mycorrhizal fungi and Aphanomyces euteiches in field-grown pea. Mycorrhiza, 12(1), 7-12. doi.org/10.1007/s00572-001-0139-4

Bonfante, P., \& Genre, A. (2010). Mechanisms underlying beneficial plant - Fungus interactions in mycorrhizal symbiosis. Nature Communications, 1(4), 111. doi.org/10.1038/ncomms 1046

Cameron, D. D., Neal, A. L., van Wees, S. C. M., \& Ton, J. (2013). Mycorrhiza-induced resistance: More than the sum of its parts? Trends in Plant Science, 18(10), 539-545. doi.org/10.1016/j.tplants.2013.06.004

Campos, M. A. da S. (2020). Bioprotection by arbuscular mycorrhizal fungi in plants infected with Meloidogyne nematodes: A sustainable alternative. Crop Protection, 135(September 2019), 105203. doi.org/10.1016/j.cropro.2020.105203

Cardoso, I. M., \& Kuyper, T. W. (2006). Mycorrhizas and tropical soil fertility. Agriculture, Ecosystems and Environment, 116(1-2), 72-84. https://doi.org/10.1016/j.agee.2006.03.011

Chandrasekaran, M. (2020). A meta-analytical approach on arbuscular mycorrhizal fungi inoculation efficiency on plant growth and nutrient uptake. Agriculture, 10(9), 1-12. doi.org/10.3390/agriculture 10090370

Diagne, N., Ngom, M., Djighaly, P. I., Fall, D., Hocher, V., \& Svistoonoff, S. (2020). Roles of arbuscular mycorrhizal fungi on plant growth and performance: importance in biotic and abiotic stressed regulation. Diversity, 12(10), 1-25. doi.org/10.3390/d12100370

Díaz-Valle, A., López-Calleja, A. C., \& Alvarez-Venegas, R. (2019). Enhancement of Pathogen Resistance in Common Bean Plants by Inoculation With Rhizobium etli. Frontiers in Plant Science, 10(October), 1-19. doi.org/10.3389/fpls.2019.01317

Evelin, H., Kapoor, R., \& Giri, B. (2009). Arbuscular mycorrhizal fungi in alleviation of salt stress: A review. Annals of Botany, 104(7), 1263-1280. doi.org/10.1093/aob/mcp251

Genre, A., Lanfranco, L., Perotto, S., \& Bonfante, P. (2020). Unique and common traits in mycorrhizal symbioses. Nature Reviews Microbiology, 18(11), 649-660. doi.org/10.1038/s41579-020-0402-3

He, Y., Pantigoso, H. A., Wu, Z., \& Vivanco, J. M. (2019). Co-inoculation of Bacillus sp. and Pseudomonas putida at different development stages acts as a biostimulant to promote growth, yield and nutrient uptake of tomato. Journal of Applied Microbiology, 127(1), 196-207. doi.org/10.1111/jam.14273

Hu, J., Wei, Z., Friman, V. P., Gu, S. H., Wang, X. F., Eisenhauer, N., Yang, T. J., Ma, J., Shen, Q. R., Xu, Y. C., \& Jousset, A. (2016). Probiotic diversity enhances rhizosphere microbiome function and plant disease suppression. MBio, 7(6), 1-8. doi.org/10.1128/mBio.01790-16

Jacott, C. N., Murray, J. D., \& Ridout, C. J. (2017). Trade-offs in arbuscular mycorrhizal symbiosis: Disease resistance, growth responses and perspectives for crop breeding. Agronomy, 7(4), 1-18. doi.org/10.3390/agronomy7040075

Jung, S. C., Martinez-Medina, A., Lopez-Raez, J. A., \& Pozo, M. J. (2012). Mycorrhiza-Induced Resistance and Priming of Plant Defenses. Journal of Chemical Ecology, 38(6), 651-664. doi.org/10.1007/s10886-012-0134-6

Kalantari, S., Marefat, A., Naseri, B., \& Hemmati, R. (2018). Improvement of bean yield and Fusarium root rot biocontrol using mixtures of Bacillus, Pseudomonas and Rhizobium. Tropical Plant Pathology, 43(6), 499-505. doi.org/10.1007/s40858-018-0252-y

Karoney, E. M., Ochieno, D. M. W., Baraza, D. L., Muge, E. K., Nyaboga, E. N., \& Naluyange, V. (2020). Rhizobium improves nutritive suitability and tolerance of Phaseolus vulgaris to Colletotrichum lindemuthianum by boosting organic nitrogen content. Applied Soil Ecology, 149(January), 103534. doi.org/10.1016/j.apsoil.2020.103534

Khatoon, Z., Huang, S., Rafique, M., Fakhar, A., Kamran, M. A., \& Santoyo, G. (2020). Unlocking the potential of plant growth-promoting rhizobacteria on soil health and the sustainability of agricultural systems. Journal of Environmental Management, 273(April), 111118. doi.org/10.1016/j.jenvman.2020.111118

Kumari, S. M. P., \& Prabina, B. J. (2019). Protection of Tomato, Lycopersicon esculentum from Wilt Pathogen, Fusarium oxysporum f.sp. lycopersici by Arbuscular Mycorrhizal Fungi, Glomus sp. International Journal of Current Microbiology and Applied Sciences, 8(04), 1368-1378. doi.org/10.20546/ijcmas.2019.804.159

Li, Y., Chapman, S. J., Nicol, G. W., \& Yao, H. (2018). Nitrification and nitrifiers in acidic soils. Soil Biology and Biochemistry, 116(November 2017), 290301. doi.org/10.1016/j.soilbio.2017.10.023 
Lin, C., Wang, Y., Liu, M., Li, Q., Xiao, W., \& Song, X. (2020). Effects of nitrogen deposition and phosphorus addition on arbuscular mycorrhizal fungi of Chinese fir (Cunninghamia lanceolata). Scientific Reports, 10(1), 1-8. doi.org/10.1038/s41598-020-69213-6

Liu, J., Maldonado-Mendoza, I., Lopez-Meyer, M., Cheung, F., Town, C. D., \& Harrison, M. J. (2007). Arbuscular mycorrhizal symbiosis is accompanied by local and systemic alterations in gene expression and an increase in disease resistance in the shoots. Plant Journal, 50(3), 529-544. doi.org/10.1111/j.1365313X.2007.03069.x

Ma, R., Zhao, W., Zhao, Y., Wang, Z., Zhu-Barker, X., Wright, A. L., \& Jiang, X. (2020). Land use pattern effects after 30 years of shifting cropland to fallow land on soil ammonia-oxidizer community. Applied Soil Ecology, 156(October 2019), 103707. doi.org/10.1016/j.apsoil.2020.103707

Mabrouk, Y., Hemissi, I., Salem, I. Ben, Mejri, S., Saidi, M., \& Belhadj, O. (2018). Potential of Rhizobia in Improving Nitrogen Fixation and Yields of Legumes. Symbiosis. doi.org/10.5772/intechopen.73495

Manhaes, C. M. C., \& Francelino, F. M. A. (2013). Biota of Soil and Its Relations With the Ecological System Root. Nucleus, 10(2), 127-137. doi.org/10.3738/1982.2278.815

Masson-Boivin, C., \& Sachs, J. L. (2018). Symbiotic nitrogen fixation by rhizobia — the roots of a success story. Current Opinion in Plant Biology, 44, 7-15. doi.org/10.1016/j.pbi.2017.12.001

Mathur, S., \& Jajoo, A. (2020). Arbuscular mycorrhizal fungi protects maize plants from high temperature stress by regulating photosystem II heterogeneity. Industrial Crops and Products, 143(September 2019), 111934. doi.org/10.1016/j.indcrop.2019.111934

Miozzi, L., Vaira, A. M., Brilli, F., Casarin, V., Berti, M., Ferrandino, A., Nerva, L., Accotto, G. P., \& Lanfranco, L. (2020). Arbuscular mycorrhizal symbiosis primes tolerance to cucumber mosaic virus in tomato. Viruses, 12(6), 1-19. doi.org/10.3390/v12060675

Omotayo, O. P., \& Babalola, O. O. (2020). Resident rhizosphere microbiome's ecological dynamics and conservation: Towards achieving the envisioned Sustainable Development Goals, a review. International Soil and Water Conservation Research, (9), 127-142. doi.org/10.1016/j.iswcr.2020.08.002

Padrão, J., Tortella, G., Cortez, S., Dias, N., Nicolau, A., \& Mota, M. (2019). Nitrifying Soil Bacterium Nitrosomonas europaea: Operational Improvement of Standard Culture Medium. Journal of Soil Science and Plant Nutrition, 19(2), 270-276. doi.org/10.1007/s42729-019-00023-0

Pereira, A. S., Shitsuka, D. M., Parreira, F. J., Shitsuka, R. (2018). Metodologia da Pesquisa Científica. Universidade Federal de Santa Maria.

Pozo, M. J., Jung, S. C., López-Ráez, J. A., Azéon-Aguilar, C. (2010). Impact of Arbuscular Mycorrhizal Symbiosis on Plant Response to Biotic Stress: The Role of Plant Defence Mechanisms. Arbuscular Mycorrhizas: Physiology and Function, 193-207. doi.org/10.1007/978-90-481-9489-6_9

Rillig, M. C. (2004). Arbuscular mycorrhizae, glomalin, and soil aggregation. Canadian Journal of Soil Science, 84(4), 355-363. doi.org/10.4141/S04-003

Sergeevich, S. A., Alexandrovich, Z. V., Yurievna, S. O., \& Yurievich, B. A. (2015). Nod-Factor Signaling in Legume-Rhizobial Symbiosis. Plants for the future, 135-160. dx.doi.org/10.5772/61165

Sikes, B. A. (2010). When do arbuscular mycorrhizal fungi protect plant roots from pathogens? Plant Signaling and Behavior, 5(6), 763-765. doi.org/10.4161/psb.5.6.11776

Song, Y., Chen, D., Lu, K., Sun, Z., \& Zeng, R. (2015). Enhanced tomato disease resistance primed by arbuscular mycorrhizal fungus. Frontiers in Plant Science, 6(September), 1-13. doi.org/10.3389/fpls.2015.00786

Spagnoletti, F. N., Cornero, M., Chiocchio, V., Lavado, R. S., \& Roberts, I. N. (2020). Arbuscular mycorrhiza protects soybean plants against Macrophomina phaseolina even under nitrogen fertilization. European Journal of Plant Pathology, 156(3), 839-849. doi.org/10.1007/s10658-020-01934-w

Tian, L., Lin, X., Tian, J., Ji, L., Chen, Y., Tran, L. S. P., \& Tian, C. (2020). Research advances of beneficial microbiota associated with crop plants. International Journal of Molecular Sciences, 21(5), 1-18. doi.org/10.3390/ijms21051792

Tian, L., Shi, S., Ma, L., Zhou, X., Luo, S., Zhang, J., Lu, B., \& Tian, C. (2019). The effect of Glomus intraradices on the physiological properties of Panax ginseng and on rhizospheric microbial diversity. Journal of Ginseng Research, 43(1), 77-85. doi.org/10.1016/j.jgr.2017.08.005

Tonelli, M. L., Figueredo, M. S., Rodríguez, J., Fabra, A., \& Ibañez, F. (2020). Induced systemic resistance -like responses elicited by rhizobia. Plant and Soil, 448(1-2), 1-14. doi.org/10.1007/s11104-020-04423-5

Trivedi, P., Leach, J. E., Tringe, S. G., Sa, T., \& Singh, B. K. (2020). Plant-microbiome interactions: from community assembly to plant health. Nature Reviews Microbiology, 18(11), 607-621. doi.org/10.1038/s41579-020-0412-1

Wang, Y. Y., Yin, Q. S., Qu, Y., Li, G. Z., \& Hao, L. (2017). Arbuscular mycorrhiza-mediated resistance in tomato against Cladosporium fulvum-induced mould disease. Journal of Phytopathology, 166(1), 67-74. doi.org/10.1111/jph.1266 